Research Article

\title{
Investigation of Drilling Process Parameters of Palmyra Based Composite
}

\author{
A. Mohan Kumar $\mathbb{D}^{1},{ }^{1}$ R. Rajasekar ${ }^{D},{ }^{1}$ P. Manoj Kumar ${ }^{(D},{ }^{2}$ R. Parameshwaran $\left(\mathbb{D},{ }^{1}\right.$ \\ Alagar Karthick $\left(\mathbb{D},{ }^{3}\right.$ V. Mohanavel $\left(\mathbb{D},{ }^{4}\right.$ T. Sakthi, ${ }^{5}$ and M. Muhibbullah ${ }^{6}{ }^{6}$ \\ ${ }^{1}$ School of Building and Mechanical Sciences, Kongu Engineering College, Perundurai 638060, Tamilnadu, India \\ ${ }^{2}$ Department of Mechanical Engineering, KPR Institute of Engineering and Technology, Coimbatore 641407, Tamilnadu, India \\ ${ }^{3}$ Department of Electrical and Electronics Engineering, KPR Institute of Engineering and Technology, 641407 Coimbatore, \\ Tamilnadu, India \\ ${ }^{4}$ Centre for Materials Engineering and Regenerative Medicine, Bharath Institute of Higher Education and Research, \\ 600073 Chennai, Tamilnadu, India \\ ${ }^{5}$ Department of Mechanical Engineering, National Engineering College, K.R. Nagar, Kovilpatti 628 503, Tamilnadu, India \\ ${ }^{6}$ Department of Electrical and Electronic Engineering, Bangladesh University, Dhaka 1207, Bangladesh
}

Correspondence should be addressed to A. Mohan Kumar; amohanmech2006@gmail.com and M. Muhibbullah; m.muhibbullah@ bu.edu.bd

Received 9 August 2021; Accepted 28 October 2021; Published 20 November 2021

Academic Editor: Jinyang Xu

Copyright (c) 2021 A. Mohan Kumar et al. This is an open access article distributed under the Creative Commons Attribution License, which permits unrestricted use, distribution, and reproduction in any medium, provided the original work is properly cited.

The drilling process is the most essential in the final assembly of the mechanical parts. Natural fiber based composites replace traditional materials due to their advantages, such as strength to weight ratio, availability, and environmental hazards. In this work, an attempt has been made to find the minimum thrust force produced by the drill tool at specified drilling process parameters. The drilling process parameters used for the investigation are rotational speed, tool feed, and resins. The spindle speed and feed rate are selected with three levels. Three resin materials were used, namely, epoxy, polyester, and vinyl ester. Taguchi's $\mathrm{L}_{27}$ orthogonal array was implemented. The result shows that the candlestick drill bit generated lesser thrust force at the specified drilling process parameters, followed by the twist and step cone drill bits.

\section{Introduction}

Environmental protection is the main focus towards the use of cellulose fiber as reinforcement in the polymer matrix. Natural fibers having many advantages compared to synthetic fibers are lightweight, available in plenty, biodegradable, and no hazards to the environment. Hence, they are used as load transfer material in composite material. However, they have few drawbacks compared to synthetic materials, such as poor resistance to water, lesser modulus, and lower strength. Few authors reported the different studies in the natural fiber based composites, namely, hemp, abaca, sisal, banana, oil palm, and wood pulp [1-3]. The strength and stiffness characteristics of the natural fiber based composite can be improved by increasing interfacial bonding of the fibers and matrixes [4].
The machining of the fiber based composite is complicated due to the property difference and the fiber orientation nature of the natural fibers reinforcement [5]. Hence, it is required special attention to analyze fiber based composite compared to homogeneous machining. During drilling of the fiber strengthened composite, the effect of the mechanical and thermal properties is more. Hence, the selection of the process factors of the drilling process and the experimental conditions is more essential to produce quality machining. During fiber based composite machining process, the manufacturing defects produced are cracks, voids, fiber pullouts, delamination, and thermal defects. The following factors are considered to determine the machinability of the fiber-reinforced composite: tool materials, tool geometry, cutting condition, and type of 
machining process [6-8]. The other factors, namely, surface roughness, roundness, and residual stress, are considered less critical.

Drilling is an essential machining process in the final assembly process of the manufacturing industry [9-13]. Different methods are used to make a hole on the fiber based composite. However, the most common traditional method has been employed. According to the forces generated during drilling, drilling is more complicated than another machining process. Few other factors affect the hole quality, namely, delamination fiber pullouts and surface roughness. To overcome the defects generated during the drilling process, it is required to develop proper experimental procedures, machining conditions, and cutting conditions $[5,14,15]$.

The composites are inclined towards delamination and fiber pullouts due to their unidirectional properties. The hole quality is checked by visual inspection that is a standard assessment method. The delamination defects may be present, namely, peel-up and push-down delamination in the drilled hole. The measurement of the delamination in the natural fiber based composite is either direct or indirect. Indirect measurement measures delamination factors such as chip produced, damage width, surface unevenness, and delamination factor. The indirect measurement includes assessment of axial force, torque, and power generation during the drilling process.

In most of the direct assessment methods of delamination, the essential parameter considered is the delamination factor. The delamination is majorly classified into two types, namely, push-down and peel-up delamination. The following parameters are considered appropriate to avoid defects during the drilling process: drill rate, cutting speed, tool shape, and experimental conditions [16]. Feito et al. [17] found the lesser axial force and delamination factor during drilling at a low drill rate using stepped drill geometry. In addition, the backplate can be used to diminish delamination factor and axial force and obtain quality holes. They stated that the best contract is obtained between the experimental results and the mathematical model. The investigation was carried out with flax-based composite and found that the defacing factor reduces with drill rate.

Additionally, different factor accounts in the numerical model have been validated with experimental results [18]. Vinayagamoorthy et al. analyzed the hole-making characteristics of the vetiver-based composite. The drill's drilling rate and point angle mainly influence the push-out defacing, but the effect of the spindle speed is very minimal. They also found that the spindle speed, drill rate, and point angle majorly influence the peel-up defacing [19]. Rezghi Maleki et al. found that the feed rate has influenced the axial force generation during drilling jute-based fibers for all drill tools. They concluded that the high-speed steel drill and CoroDrill 856 contribute more to the generation of axial force and surface unevenness during drilling compared to CoroDrill 854 , feed rate $0.15 \mathrm{~mm} / \mathrm{rev}$, and rotational speed $1250 \mathrm{rpm}$ that are very much suitable for drilling of jute-based composite with minimum drilling defects [20]. Rezghi Maleki et al. repeated the same investigation to the flax- based fibers and found that the high-speed drill influences the thrust force generated more than the CoroDrill 856 and CoroDrill 854 drill bits. They also reported that the hole quality and delamination factor influence the different geometrical drill bits more than the spindle speed and drill rate [21]. Patel et al. investigated the drilling characteristics of the hybrid composite, namely, basalt/glass, the tool geometry, and the lamination sequences effects of peel-up and push-down delamination. The parabolic geometry of the drill bit with high feed shows lesser delamination at exit. They concluded that the low spindle speed, low feed, and parabolic geometry drill bit are very much suitable for drilling hybrid composites to produce high quality holes [22]. Pradeep and Rajasekaran [23] analyzed the drilling behavior in chopped jute-based fiber, and three different drill tool materials are used, namely, high-speed steel, cobalt steel, and tungsten carbide. The axial force required to make the hole is lesser for the tungsten drill bit than other drill bits. Bajpai and Singh [24] found the drilling characteristics of the sisal fiber based composite, and two different geometrical drill bits have been used, namely, twist and trepanning tools. The thrust force generated by the trepanning tool is much lower compared to the twist tool. They concluded that the hollow drill bit might be suitable to drill natural fiberreinforced composites. The drilling process parameters, namely, spindle speed, drill rate, and the drill geometries, are influenced much more by the defacing factor and drilling forces (axial force and torque) during drilling of sisal/optiva natural fiber based composites. Among the process parameters, the drill bit geometry contributes more to the defacing factor [25]. Roy Choudhury et al. [26] examined drilling-induced delamination, forces, and induced temperature produced during the drilling process experimentally. The five different geometric drill bits have been used for the investigation. Turki et al. [27] inspected the influence of fiber alignment on the delamination damage and thrust force. The friction-induced between the tool and the composite surfaces is examined by the temperature developed during the carbon fiber-reinforced epoxy composite specimen. The assessment between the thrust force and the defacing factor of two dissimilar geometrical drill bits on the flax-based composites has been carried out. They also found that the feed rate affects more the induced damage during drilling in the composite specimen [28].

The delamination defect, namely, peel-up occurred at the tool entrance of the composite specimen. When the tool starts to pierce the surface of the specimen, it generates peelup force in the axial direction, and it separates the laminates. The delamination degree will depend on the rotational speed and point angle. The push-down delamination happens at the exit of the drilled hole. This is because the resistive force offered by the exit laminae is lesser than the axial force of the tool. Hence, it generates exit delamination [29]. Belaadi et al. [30] investigated the drilling process parameters with four different geometrical drill bits, and response surface methodology and artificial neural networks are used to authenticate the experimental values. The two techniques obtained from the artificial neural network are closer to the experimental value than the response surface methodology. 
Rajaraman et al. [31] examined the process parameters of drilling on the kenaf and banana-based composite. The highspeed steel of three different diameters and the L9 factorial method has been used for the experimental study. They concluded that the spindle speed of $3000 \mathrm{rpm}$ and $150 \mathrm{~mm} /$ min has been suitable for defect-free holes. Panneerselvam et al. [32] investigated the drilling on the sisal/glass hybrid composite and found that the drilling rate influences the exit defacing more. They used a profile projector, and image processing software was used to examine the defects in the holes. Abilash and Sivapragash [33] evaluated the effect of the induced force during drilling of bamboo-based composites and developed the regression modelling to reduce exit delamination. Ramesh et al. [34] investigated the drilling defects in hybrid composites, which consist of the sisal/glass, also found that the axial force is enhanced with drill rate, and obtained the maximum value for high-speed steel tool.

The availability of Palmyra fiber is plenty in south zone of India especially in Tamilnadu. It made interesting investigation on optimization of drilling parameters during drilling of Palmyra based composite. Only few papers are available on characteristic study of Palmyra based composite. However, there are no research papers available for drilling parameters optimization of Palmyra based composites. Hence, in this investigation, an attempt has been made to find the most appropriate drilling process parameters to reduce drilling defects. One appropriate drill bit has been suggested with optimum drilling process parameters among the two different geometrical drill bits used for this investigation. As per Taguchi's design of the experiment $\mathrm{L}_{27}$ model has been used for investigation. Table 1 shows the methodology of investigation on drilling process parameters of Palmyra based composite.

\section{Materials and Methods}

The three matrices have been used for the investigation, namely, epoxy, polyester, and vinyl ester. The density and viscosity of epoxy at $25^{\circ} \mathrm{C}$ are $1.16 \mathrm{gm} / \mathrm{cm}^{3}$ and $900 \mathrm{cps}$, respectively. The hardener used is 3 diacid anhydride. The density and viscosity of vinyl ester at $25^{\circ} \mathrm{C}$ are $1.052 \mathrm{gm} / \mathrm{cm}^{3}$ and $325 \mathrm{cps}$, respectively. For polyester, the density and viscosity at $25^{\circ} \mathrm{C}$ are $1.12 \mathrm{gm} / \mathrm{cm}^{3}$ and $500 \mathrm{cps}$, respectively. These are purchased from the Aypols private limited Coimbatore. Methyl ethyl ketone peroxide and cobalt activator are used as curing system for vinyl ester and polyester resin, respectively. The Palmyra sprout fiber extracted from the Palmyra sprout fruit (Borassus flabellifer) is shown in Figure 1. Sipcon vertical profile projector has been used to view outer periphery of the drilled hole. The resolution of the profile projector is up to 0.5 micrometer.

2.1. Experimental Setup. The investigation has been carried out in Computer Numerical Control (CNC) vertical machining center. The maximum spindle speed, power, and machine axis are $40,000 \mathrm{rpm}, 5 \mathrm{~kW}$, and 3 . The drill tool dynamometer is of $50 \mathrm{~Hz}$ frequency, with the axial measuring range $0-50000 \mathrm{~N}$ fixed in the CNC platform as shown in Figure 2. The drilling tool is $6 \mathrm{~mm}$ carbide, and different geometries were used, namely, standard twist, candlestick, and step cone drill bits, as shown in Figure 3. Three levels of rotational speed and drill rate have feed considered for investigation. Three levels of rotational speed are 1000, 1500, and $2000 \mathrm{rpm}$. Three levels of feed are $0.1,0.15$, and $0.2 \mathrm{~mm} /$ rev.

2.2. Composite Fabrication. The Palmyra sprout fiber is cleaned and chopped with 5 to $10 \mathrm{~cm}$ length. The range of diameter is 0.05 to $2 \mathrm{~cm}$. The fibers are dried under vacuum for 3 hours at the temperature of $60^{\circ} \mathrm{C}$ [35]. The palmyra sprout fiber-reinforced polyester, vinyl ester, and epoxy are made up of hand layup process and compression moulding techniques. The fibers are randomly oriented, and steel rollers have been used to form an even surface of the specimen. The uniform thickness of the specimen has been obtained by the hydraulic press for 4 hours. The curing reagent of $1 \mathrm{Vol} \%$ has been used for fast curing. The composite specimen has been allowed to cool for 24 hours at atmospheric temperature. The required dimension of $30 \mathrm{~cm} * 3 \mathrm{~cm} * 0.3 \mathrm{~cm}$ was obtained as shown in Figure 4 .

2.3. Taguchi Method. The Taguchi method of optimization has been selected for this study due to the three process parameters, three levels, and one response parameters, and $\mathrm{L}_{27}$ full factorial method has been implemented. The output influencing parameters are listed in the orthogonal array Table 1. The $\mathrm{L}_{27}$ orthogonal array test can be conducted to minimize a large number of experiments. The maximum signal to noise ratio value is considered the best value to minimize the thrust force value. A loss function has been characterized to determine the difference between the experimental value and the standard value. The process behavior is characteristic of three types: the smaller the better, the nominal the better, and the higher the better .

$$
\text { Lower }- \text { the }- \text { better }=-10 \log \left(\frac{1}{n} \sum_{i=1}^{n} y_{t}^{2}\right)
$$

where $n=$ number of replications and $y_{t}=$ tensile strength for the $i^{\text {th }}$ trial.

\section{Results and Discussion}

Many researches prove that the defects produced during drilling of the fiber based composites depend on the thrust force produced during drilling $[8,15,34]$. The axial force was determined using different geometrical drill bits to drill the palmyra fiber-reinforced epoxy, polyester, and vinyl ester composites. The three drill bits used for the analysis are the candlestick, twist, and step one. The axial force generated during drilling of Palmyra fiber based composite is listed in the Table 1. The $\mathrm{L}_{27}$ orthogonal array is used with three drilling process factors: resin, rotational speed, and drill rate. Three levels of spindle speed are 1000, 1500, and $2000 \mathrm{rpm}$. Three levels of feed are $0.1,0.15$, and $0.2 \mathrm{~mm} / \mathrm{rev}$. The axial force generated by the three drill tools shown in Table 2 
TABLE 1: Methodology of investigation on drilling process parameters of Palmyra based composite.

\begin{tabular}{lcc}
\hline Materials & Fibers & $\begin{array}{c}\text { Palmyra sprout fruit } \\
\text { Epoxy } \\
\text { Polyester } \\
\text { Vinyl ester }\end{array}$ \\
\hline Drilling process parameters & Resins & $1000,1500,2000$ \\
& Speed $(\mathrm{rpm})$ & $0.10,0.15,0.20$ \\
Experimental setup & Feed $(\mathrm{mm} / \mathrm{rev})$ & Thrust force (N) \\
& Desponse parameter & Candlestick, standard twist, and Stepcone drill \\
Optimization of process parameters & Fabrication method & Hachine \\
\hline
\end{tabular}

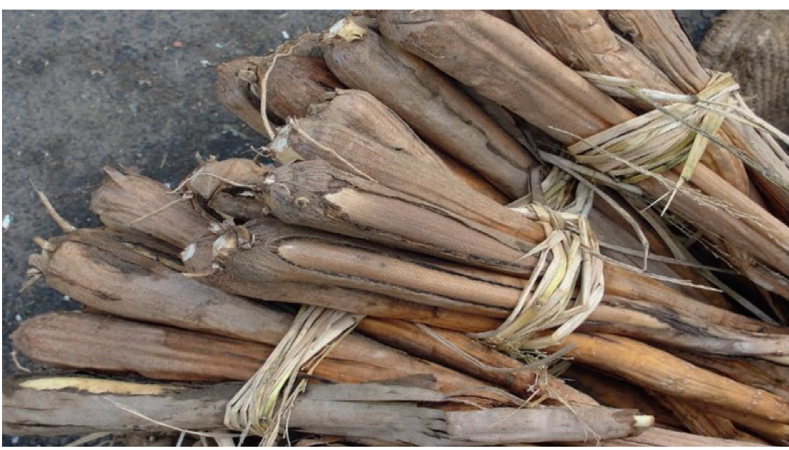

(a)

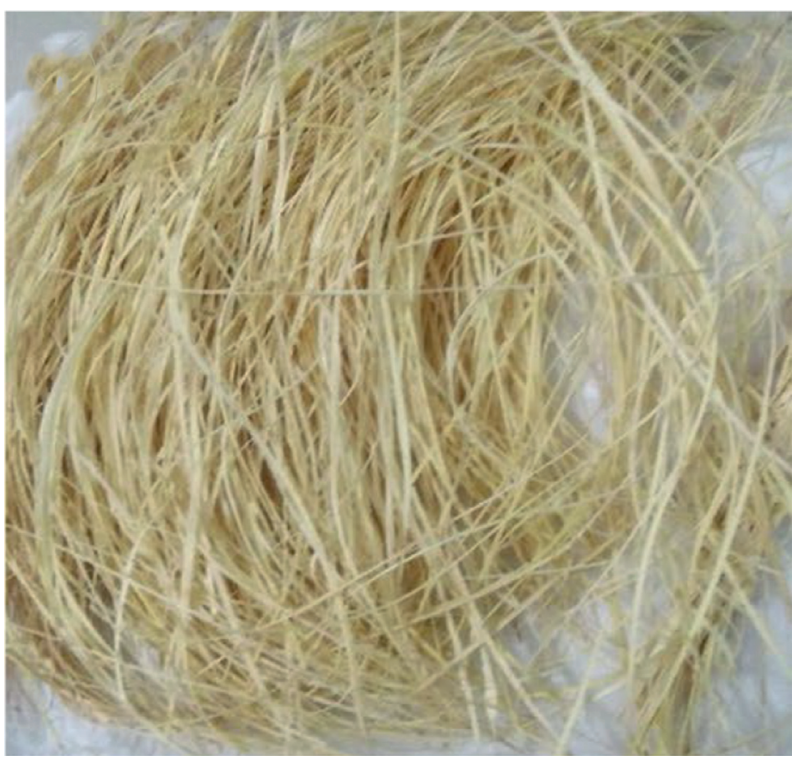

(b)

Figure 1: (a) Palmyra sprout fruit. (b) Palmyra sprout fiber.

varies from $7.39 \mathrm{~N}$ to $12.83 \mathrm{~N}$. The axial force generated by the candlestick drill bit is lesser than that of other drill bits. At $1000 \mathrm{rpm}$ and $0.2 \mathrm{~mm} / \mathrm{rev}$, the axial force generated by the candlestick is minimum. The smaller it is, the better option has been considered for the $\mathrm{S} / \mathrm{N}$ ratio to find the deviation from the desired value as shown in Figure 5. Since lesser thrust force is required, the smaller, the better $\mathrm{S} / \mathrm{N}$ ratio selected for the study.

At $1000 \mathrm{rpm}$ rotational speed, and $0.2 \mathrm{~mm} / \mathrm{rev}$ axial feed, the drilled hole of the Palmyra reinforced epoxy specimen by candlestick drill bit has been viewed using profile projector as shown in Figure 6. The specimen has been cut laterally and viewed using profile projector; it is clear that the defects on the specimen at specified speed, feed, and drill bit are lower compared with the drilled hole at different speeds and feeds.

Figure 5 shows the Signal to Noise (S/N) ratio during drilling of Palmyra based composite. Figure 5(a) shows the $\mathrm{S} / \mathrm{N}$ ratio of thrust force generated by the candlestick drill bit. The lower $\mathrm{S} / \mathrm{N}$ ratio value is shown at $1000 \mathrm{rpm}$ and $0.2 \mathrm{~mm} / \mathrm{rev}$. Similarly, at $1000 \mathrm{rpm}$ and $0.2 \mathrm{~mm} / \mathrm{rev}$, the $\mathrm{S} / \mathrm{N}$ ratio of thrust force produced by the twist drill has a minimum, as shown in Figure 5(b). At $2000 \mathrm{rpm}$ and $0.2 \mathrm{~mm} / \mathrm{rev}$, the $\mathrm{S} / \mathrm{N}$ ratio of thrust force produced by the step cone drill bit has a minimum, as shown in Figure 5(c).

The signal to noise ratio of spindle speed is increased to $18.5 \%$ and $92.59 \%$ for $1500 \mathrm{rpm}$ and $2000 \mathrm{rpm}$, respectively, compared to $1000 \mathrm{rpm}$ for the candlestick drill bit during the drilling process Figure 5(a). It implies that the spindle speed increases with the increase in the thrust force value. For candlestick drills, the thrust force value is significantly influenced by the spindle speed. Similarly, the signal to noise ratio during drilling of the composite by standard twist drill is increased to $59.09 \%$ and $50 \%$ for the spindle speed of $1500 \mathrm{rpm}$ and $2000 \mathrm{rpm}$, respectively, compared to $1000 \mathrm{rpm}$ as shown in the Figure 5(b). In contrast, the signal to noise ratio decreases to $32.2 \%$ and $12.9 \%$ for the step cone drill bit 


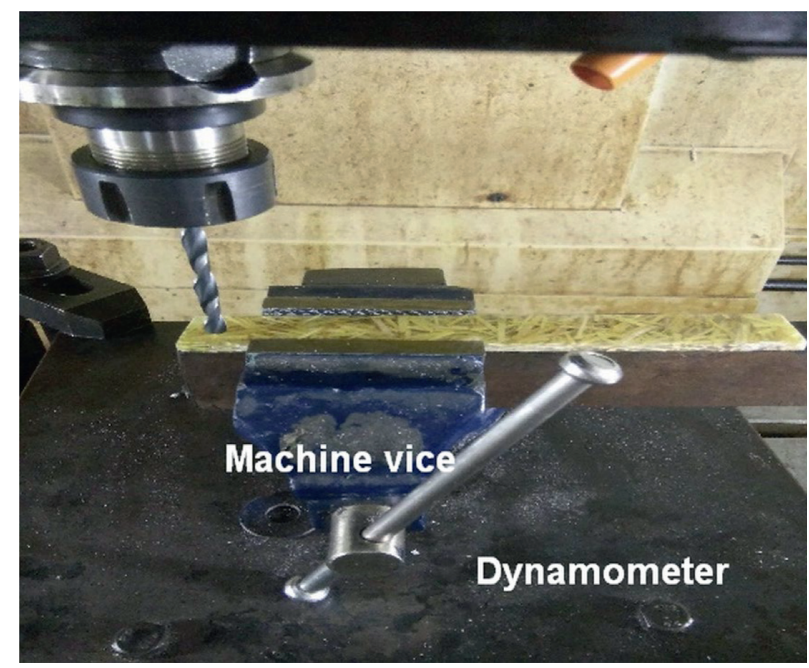

Figure 2: Drilling experimental setup.

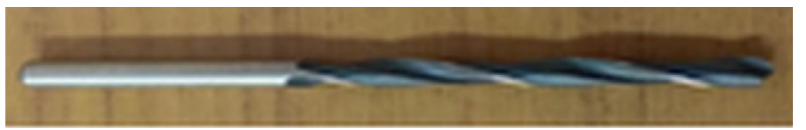

(a)

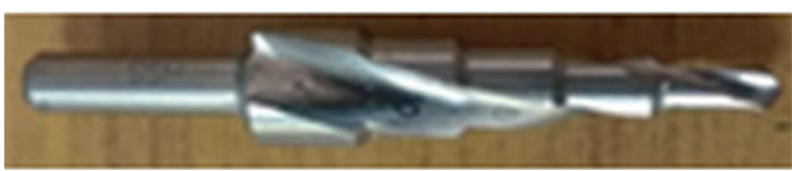

(b)

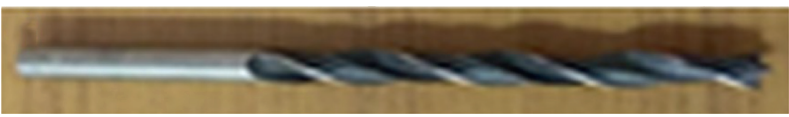

(c)

Figure 3: (a) Standard twist drill, (b) step cone drill, and (c) candlestick drill tools.

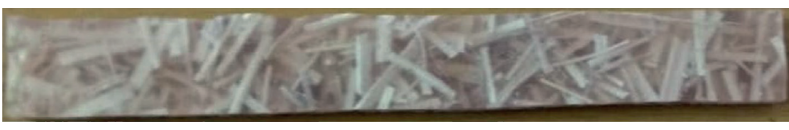

(a)

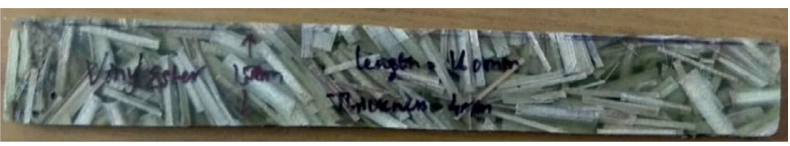

(b)

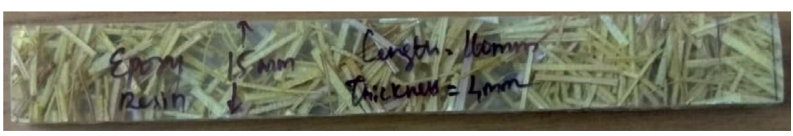

(c)

Figure 4: Palmyra sprout fiber-reinforced (a) polyester, (b) vinyl ester, and (c) epoxy composites specimen.

for spindle speed $2000 \mathrm{rpm}$ and $1500 \mathrm{rpm}$, respectively, compared to the $1000 \mathrm{rpm}$ as shown in Figure 5(c). The signal to noise ratio increases with the increase in the spindle speed for the candlestick and twist drill bit. In contrast, the signal to noise ratio decreases with spindle speed for the step cone drill bit. The statistical significance of the spindle on the thrust force generated by the candlestick drill bit is very high compared to the other drill bits. The thrust force values greatly reduced at $1000 \mathrm{rpm}$ spindle speed due to the forces generated, as drill bit A has been transferred to the outer periphery compared to the other drill bits.

For the candlestick drill bit, the tool feed's signal to noise ratio increases to $0.15 \mathrm{~mm} / \mathrm{rev}$ and then decreases, as shown in Figure 5(a). The percentage of the signal to noise ratio of tool feed increases to $32.35 \%$ and then decreases to $67.85 \%$, corresponding to $0.15 \mathrm{~mm} / \mathrm{rev}$ and $0.20 \mathrm{~mm} / \mathrm{rev}$, respectively. The same trend has been followed for the other drill bit also; for a standard twist drill, the signal to noise ratio of tool feed increases to $10.34 \%$ and then decreases to $18.5 \%$, corresponding to the $0.15 \mathrm{~mm} / \mathrm{rev}$ and $0.2 \mathrm{~mm} / \mathrm{rev}$, respectively. Likewise, the signal to noise ratio of tool feed increases to $1.38 \%$ and then decreases to $12.12 \%$, corresponding to the $0.15 \mathrm{~mm} / \mathrm{rev}$ and $0.2 \mathrm{~mm} / \mathrm{rev}$, respectively. The statistical importance of the tool feed on the thrust force generated by the candlestick drill bit is very high compared to other drill bits. The thrust force values greatly reduced at 
TABLE 2: Thrust force generated by the candlestick, standard twist, and step cone drill bits during the drilling process.

\begin{tabular}{|c|c|c|c|c|c|c|}
\hline S. no & Resin & Speed (rpm) & $\begin{array}{c}\text { Feed } \\
(\mathrm{mm} / \mathrm{rev})\end{array}$ & Thrust force by candlestick $(\mathrm{N})$ & Thrust force by a twist drill & $\begin{array}{l}\text { Thrust force by step cone } \\
\text { drill }\end{array}$ \\
\hline 1 & Epoxy & 1000 & 0.10 & 08.153 & 10.371 & 11.232 \\
\hline 2 & Epoxy & 1000 & 0.15 & 09.292 & 10.674 & 11.331 \\
\hline 3 & Epoxy & 1000 & 0.20 & 07.392 & 10.998 & 10.459 \\
\hline 4 & Epoxy & 1500 & 0.10 & 10.169 & 10.370 & 12.981 \\
\hline 5 & Epoxy & 1500 & 0.15 & 09.125 & 10.458 & 10.600 \\
\hline 6 & Epoxy & 1500 & 0.20 & 10.023 & 10.566 & 10.968 \\
\hline 7 & Epoxy & 2000 & 0.10 & 09.674 & 10.234 & 12.259 \\
\hline 8 & Epoxy & 2000 & 0.15 & 10.359 & 10.356 & 12.657 \\
\hline 9 & Epoxy & 2000 & 0.20 & 09.129 & 10.554 & 11.227 \\
\hline 10 & Polyester & 1000 & 0.1 & 09.627 & 10.369 & 11.599 \\
\hline 11 & Polyester & 1000 & 0.15 & 10.522 & 10.273 & 11.451 \\
\hline 12 & Polyester & 1000 & 0.20 & 08.439 & 10.123 & 11.348 \\
\hline 13 & Polyester & 1500 & 0.10 & 10.438 & 10.262 & 11.117 \\
\hline 14 & Polyester & 1500 & 0.15 & 10.566 & 10.178 & 10.573 \\
\hline 15 & Polyester & 1500 & 0.20 & 10.635 & 10.019 & 11.896 \\
\hline 16 & Polyester & 2000 & 0.10 & 09.534 & 10.198 & 10.693 \\
\hline 17 & Polyester & 2000 & 0.15 & 08.356 & 09.956 & 13.893 \\
\hline 18 & Polyester & 2000 & 0.20 & 09.259 & 09.897 & 11.354 \\
\hline 19 & Vinyl ester & 1000 & 0.10 & 08.933 & 10.595 & 11.400 \\
\hline 20 & Vinyl ester & 1000 & 0.15 & 09.875 & 10.097 & 11.366 \\
\hline 21 & Vinyl ester & 1000 & 0.20 & 08.996 & 09.899 & 10.289 \\
\hline 22 & Vinyl ester & 1500 & 0.10 & 10.544 & 10.480 & 11.090 \\
\hline 23 & Vinyl ester & 1500 & 0.15 & 09.153 & 10.569 & 11.199 \\
\hline 24 & Vinyl ester & 1500 & 0.20 & 09.756 & 10.668 & 13.288 \\
\hline 25 & Vinyl ester & 2000 & 0.10 & 09.432 & 10.393 & 12.639 \\
\hline 26 & Vinyl ester & 2000 & 0.15 & 09.356 & 10.456 & 12.156 \\
\hline 27 & Vinyl ester & 2000 & 0.20 & 08.289 & 09.754 & 10.887 \\
\hline
\end{tabular}

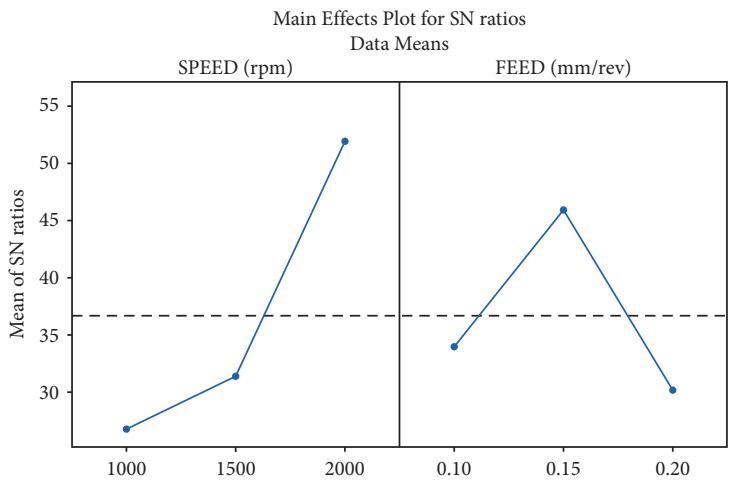

(a)

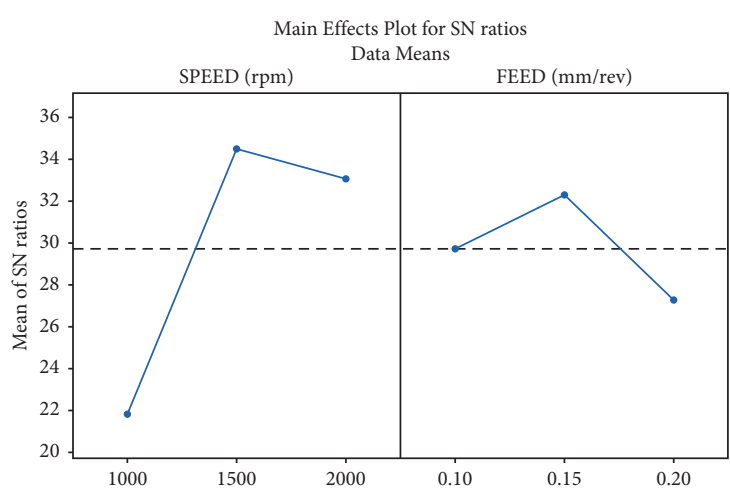

(b)

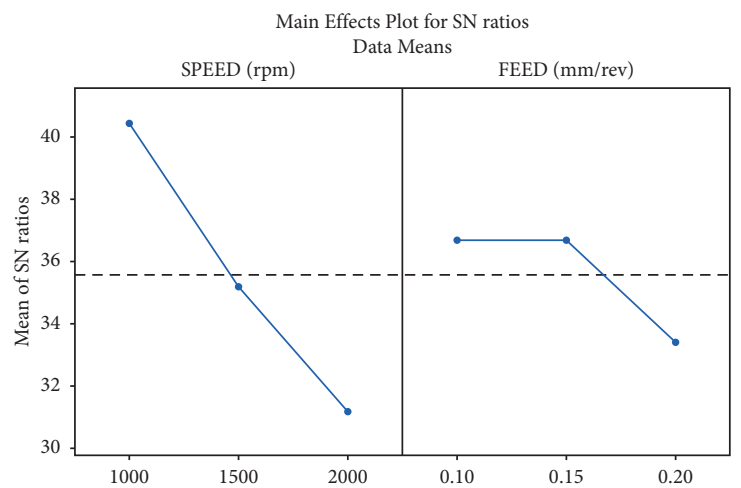

(c)

FIGURE 5: Signal-noise ratio of (a) candlestick, (b) twist, and (c) step cone drill bits during the drilling process. 

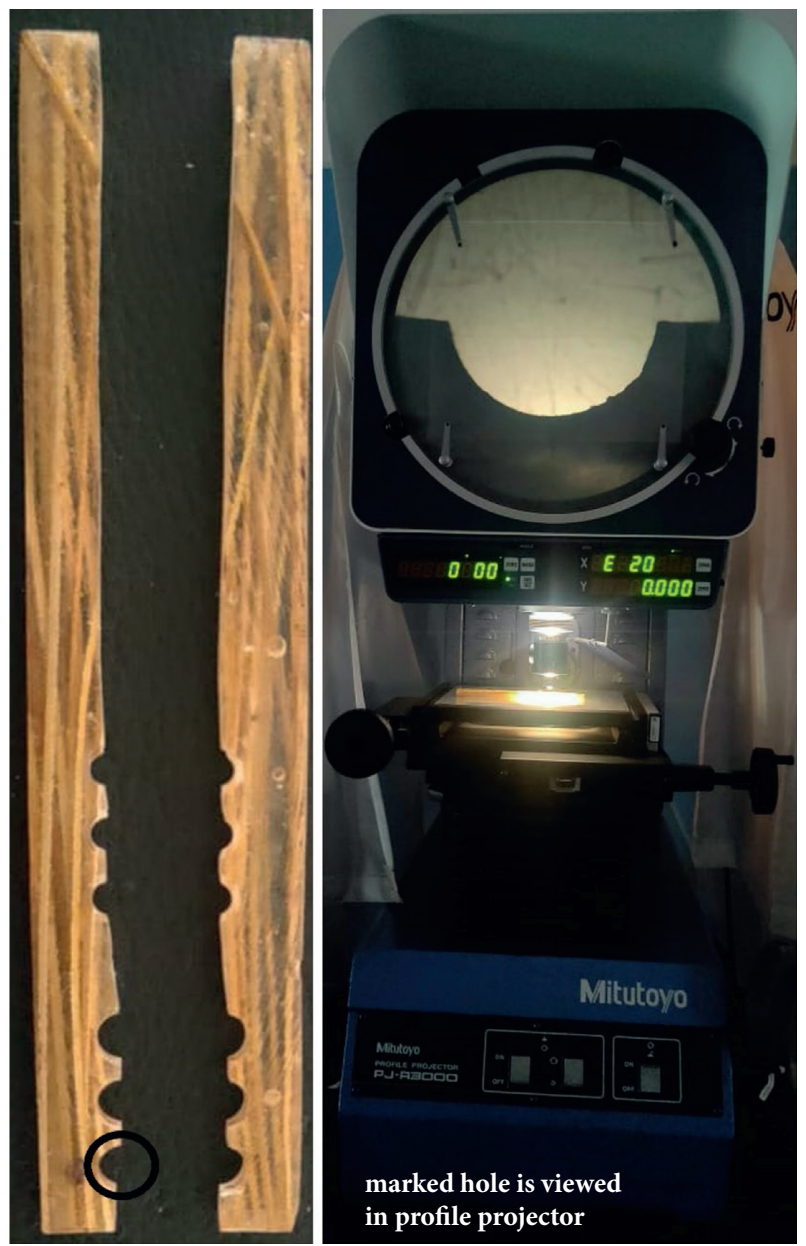

FIGURE 6: Periphery of the drilled hole is viewed using profile projector.

$0.2 \mathrm{~mm} / \mathrm{rev}$ feed rate, because the forces generated during drill bit A have been transferred to the outer periphery compared to the other drill bits. The suitable spindle speed and feed rate are $1000 \mathrm{rpm}$ and $0.2 \mathrm{~mm} / \mathrm{rev}$, respectively, to drill Palmyra reinforced epoxy composites.

The defects generated during drilling of Palmyra reinforced epoxy resin depend on the thrust force generated during drilling $[8,15,34]$. In previous studies, it is evident that the peel-up and push-down defects at the entry and exit, respectively, are formed during drilling. Hence, this work aims to reduce thrust force and achieve defect-free hole. Among the three different geometrical drill bits, the candlestick drill bit distributes the axial force into the outer circumferential of the hole. This may be the reason for the lower thrust force. The twist and step cone drill bit transmit thrust force in the axial direction; hence, the thrust force generated at the end of the composite specimen is higher due to the tool's axial force exceeding the adhesive force of uncut thickness the composite specimen $[36,37]$.

\section{Conclusion}

The drilling analysis has been carried out on the Palmyra based composites. Three process parameters have been selected for the investigation: resin, rotational speed, and drill rate. The three levels of rotational speed and drill rate have been chosen for the study. The result shows that the axial force generated by the candlestick drill bit during the drilling process has a minimum. It is followed by the twist and step cone drill bits. At lower rotational speed and higher drill rate, the thrust force generated by the candlestick and the twist drill has a minimum. Likewise, at the maximum rotational speed and higher drill rate, the axial force produced by the step cone drill bit is minimum. The minimum axial force produced by the candlestick drill tool is distributed to the tool's outer periphery. The thrust force of the drill tool exceeds the adhesive force of uncut thickness of the composite specimen, and it may be the cause for the higher axial force of twist and step cone drill bits.

\section{Data Availability}

The data used to support the findings of this study are included in the article.

\section{Conflicts of Interest}

The authors declare that there are no conflicts of interest regarding the publication of this article.

\section{Acknowledgments}

This research work is not funded by any organization.

\section{References}

[1] A. M. Kumar, R. Parameshwaran, P. S. Kumar et al., "Effects of abaca fiber reinforcement on the dynamic mechanical behavior of vinyl ester composites," Materials Testing, vol. 59, no. 6, pp. 555-562, 2017.

[2] A. Mohan Kumar, M. Gowthaman, M. Harikrishnan, and A. Kesava nanthanan, "Investigation of mechanical behavior of palmyra palm petiole fiber reinforced epoxy composites," Materials Today: Proceedings, vol. 45, pp. 1417-1422, 2021.

[3] M. S. Sreekala and S. Thomas, "Utilization of short oil palm empty fruit bunch fiber (OPEFB) as a reinforcement in phenol-formaldehyde resins: studies on mechanical properties," Journal of Polymer Engineering, vol. 16, no. 4, pp. 265-294, 1996.

[4] K. Yoganandam, V. Shanmugam, A. Vasudevan et al., "Investigation of dynamic, mechanical, and thermal properties of Calotropis procera particle-reinforced PLA biocomposites," Advances in Materials Science and Engineering, vol. 2021, Article ID 2491489, 2021

[5] V. Kavimani, B. Stalin, P. M. Gopal, M. Ravichandran, and M. Bharani, "Application of r-GO-MMT hybrid nanofillers for improving strength and flame retardancy of epoxy/glass fibre composites," Advances in Polymer Technology, vol. 2021, Article ID 6627743, 2021.

[6] P. P. Gohil, V. Chaudhary, and K. Patel, "Challenges in machining of natural fibre composites," in Manufacturing of Natural Fibre Reinforced Polymer Composites, pp. 139-153, Springer, Berlin, Germany, 2015.

[7] J. P. Davim, F. Mata, V. N. Gaitonde, and S. R. Karnik, "Machinability evaluation in unreinforced and reinforced PEEK composites using response surface models," Journal of 
Thermoplastic Composite Materials, vol. 23, no. 1, pp. 5-18, 2010.

[8] R. Parameshwaran, A. Mohan kumar, R. Rajasekar, V. C. Harissh Ragavendra, and N. Praveenraj, "Effect of thrust force, torque, and induced temperature on Kevlar reinforced composites during drilling process," Materials Today: Proceedings, vol. 45, pp. 522-528, 2021.

[9] V. Manikandan, J. T. Winowlin Jappes, S. M. Suresh Kumar, and P. Amuthakkannan, "Investigation of the effect of surface modifications on the mechanical properties of basalt fibre reinforced polymer composites," Composites Part B: Engineering, vol. 43, no. 2, pp. 812-818, 2012.

[10] C. Duraipandi, A. Khan M, J. J. T. Winowlin, N. M. Ghazaly, and P. M. Mashinini, "Solid particle erosion studies of thermally deposited alumina-titania coatings on an aluminum alloy," International Journal of Minerals, Metallurgy and Materials, vol. 28, no. 7, pp. 1186-1193, 2021.

[11] K. Ganesan, C. Kailasanathan, N. Rajini et al., "Assessment on hybrid jute/coir fibers reinforced polyester composite with hybrid fillers under different environmental conditions," Construction and Building Materials, vol. 301, Article ID 124117, 2021.

[12] K. Sudalaiyandi, K. Alagar, M. P. Vj, and P. Madhu, "Performance and emission characteristics of diesel engine fueled with ternary blends of linseed and rubber seed oil biodiesel," Fuel, vol. 285, Article ID 119255, 2021.

[13] M. Vetrivel Sezhian, K. Giridharan, D. Peter Pushpanathan, G. Chakravarthi, B. Stalin, and M. Bharani, "Microstructural and mechanical behaviors of friction stir welded dissimilar AA6082-AA7075 joints," Advances in Materials Science and Engineering, vol. 2021, Article ID 4113895, 2021.

[14] S. D. Kumar, M. Ravichandran, A. Jeevika, B. Stalin, C. Kailasanathan, and A. Karthick, "Effect of ZrB2 on microstructural, mechanical and corrosion behaviour of aluminium (AA7178) alloy matrix composite prepared by the stir casting route," Ceramics International, vol. 47, no. 9, pp. 12951-12962, 2021.

[15] S. Senthilkumar, A. Karthick, R. Madavan et al., "Optimization of transformer oil blended with natural ester oils using Taguchi-based grey relational analysis," Fuel, vol. 288, Article ID 119629, 2021.

[16] L. M. P. Durão, D. J. S. Gonçalves, J. M. R. S. Tavares et al., "Drilling delamination outcomes on glass and sisal reinforced plastics," in Materials Science ForumTrans Tech Publ, Switzerland, 2013.

[17] N. Feito, J. Díaz-Álvarez, J. López-Puente, and M. H. Miguelez, "Experimental and numerical analysis of step drill bit performance when drilling woven CFRPs," Composite Structures, vol. 184, pp. 1147-1155, 2018.

[18] A. Díaz-Álvarez, J. Díaz-Álvarez, N. Feito, and C. Santiuste, "Drilling of biocomposite materials: modelling and experimental validation," Simulation Modelling Practice and Theory, vol. 106, Article ID 102203, 2021.

[19] R. Vinayagamoorthy, I. V. Manoj, G. Narendra Kumar, I. Sai Chand, G. V. Sai Charan Kumar, and K. Suneel Kumar, "A central composite design based fuzzy logic for optimization of drilling parameters on natural fiber reinforced composite," Journal of Mechanical Science and Technology, vol. 32, no. 5, pp. 2011-2020, 2018.

[20] H. Rezghi Maleki, M. Hamedi, M. Kubouchi, and Y. Arao, "Experimental study on drilling of jute fiber reinforced polymer composites," Journal of Composite Materials, vol. 53, no. 3, pp. 283-295, 2019.
[21] H. Rezghi Maleki, M. Hamedi, M. Kubouchi, and Y. Arao, "Experimental investigation on drilling of natural flax fiberreinforced composites," Materials and Manufacturing Processes, vol. 34, no. 3, pp. 283-292, 2019.

[22] N. Patel, K. Patel, V. Chaudhary, and P. Gohil, "Investigations on drilling of hybrid basalt/glass polyester composites," Australian Journal of Mechanical Engineering, vol. 2020, Article ID 1784560, 10 pages, 2020.

[23] S. Pradeep and T. Rajasekaran, "Cutting force analysis on drilling of natural fiber reinforced polymer composites material," in Techno-Societal 2018, pp. 561-571, Springer, Berlin, Germany, 2020.

[24] P. K. Bajpai and I. Singh, "Drilling behavior of sisal fiberreinforced polypropylene composite laminates," Journal of Reinforced Plastics and Composites, vol. 32, no. 20, pp. 1569-1576, 2013.

[25] P. K. Bajpai, K. Debnath, and I. Singh, "Hole making in natural fiber-reinforced polylactic acid laminates," Journal of Thermoplastic Composite Materials, vol. 30, no. 1, pp. 30-46, 2017.

[26] M. Roy Choudhury, M. S. Srinivas, and K. Debnath, "Experimental investigations on drilling of lignocellulosic fiber reinforced composite laminates," Journal of Manufacturing Processes, vol. 34, pp. 51-61, 2018.

[27] Y. Turki, M. Habak, R. Velasco, and P. Vantomme, "Highlighting cutting mechanisms encountered in carbon/epoxy composite drilling using orthogonal cutting," International Journal of Advanced Manufacturing Technology, vol. 92, 2017.

[28] A. Díaz-Álvarez, Á. Rubio-López, C. Santiuste, and M. H. Miguélez, "Experimental analysis of drilling induced damage in biocomposites," Textile Research Journal, vol. 88, no. 22, pp. 2544-2558, 2018.

[29] D. Chandramohan and K. Marimuthu, "Drilling of natural fiber particle reinforced polymer composite material," International Journal of Advanced Engineering Research and Studies, vol. 1, no. 1, pp. 134-145, 2011.

[30] A. Belaadi, M. Boumaaza, S. Amroune, and M. Bourchak, "Mechanical characterization and optimization of delamination factor in drilling bidirectional jute fibre-reinforced polymer biocomposites," International Journal of Advanced Manufacturing Technology, vol. 111, no. 7, pp. 2073-2094, 2020.

[31] G. Rajaraman, S. K. Agasti, and M. P. Jenarthanan, "Investigation on effect of process parameters on delamination during drilling of kenaf-banana fiber reinforced in epoxy hybrid composite using Taguchi method," Polymer Composites, vol. 41, no. 3, pp. 994-1002, 2020.

[32] T. Panneerselvam, S. Raghuraman, T. K. Kandavel, and K. Mahalingam, "Evaluation and analysis of delamination during drilling on sisal-glass fibres reinforced polymer," Measurement, vol. 154, Article ID 107462, 2020.

[33] N. Abilash and M. Sivapragash, "Optimizing the delamination failure in bamboo fiber reinforced polyester composite," Journal of King Saud University - Engineering Sciences, vol. 28, no. 1, pp. 92-102, 2016.

[34] M. Ramesh, K. Palanikumar, and K. H. Reddy, "Influence of tool materials on thrust force and delamination in drilling sisal-glass fiber reinforced polymer (S-GFRP) composites," Procedia Materials Science, vol. 5, pp. 1915-1921, 2014.

[35] M. S. Huda, L. T. Drzal, A. K. Mohanty, and M. Misra, "Effect of fiber surface-treatments on the properties of laminated biocomposites from poly(lactic acid) (PLA) and kenaf fibers," Composites Science and Technology, vol. 68, no. 2, pp. 424-432, 2008. 
[36] P. M. Kumar and K. Mylsamy, "A comprehensive study on thermal storage characteristics of nano- $\mathrm{CeO} 2$ embedded phase change material and its influence on the performance of evacuated tube solar water heater," Renewable Energy, vol. 162, pp. 662-676, 2020.

[37] H. Hocheng and C. Tsao, "Effects of special drill bits on drilling-induced delamination of composite materials," International Journal of Machine Tools and Manufacture, vol. 46, no. 12-13, pp. 1403-1416, 2006. 